\title{
MODELOS DE EXPANSÃO FLORESTAL NO SEGUNDO PLANALTO PARANAENSE: UMA ANÁLISE A PARTIR DO PERFIL SOCIOECONÔMICO DOS PROPRIETÁRIOS RURAIS
}

\author{
Roberto Rochadelli ${ }^{1}$, João Carlos Garzel Leodoro da Silva ${ }^{2}$, Alessandro Vinicios Schneider ${ }^{3}$, \\ Marina Sinicio de Barros ${ }^{4}$ \\ ${ }^{1}$ Eng. Florestal, Dr., Depto. Economia Rural e Extensão, UFPR, Palotina, PR, Brasil - nashtell@ufpr.br \\ ${ }^{2}$ Eng. Florestal, Dr., Depto. Economia Rural e Extensão, UFPR, Curitiba, PR, Brasil - garzel@ufpr.br \\ ${ }^{3}$ Administrador, M.Sc., UNIMEO/CTESOP, Curitiba, PR, Brasil - schneideravs@ig.com.br \\ ${ }^{4} \mathrm{Eng}^{\mathrm{a}}$. Florestal, Curitiba, PR, Brasil - msinicio@hotmail.com
}

Recebido para publicação: 10/03/2008 - Aceito para publicação: 28/04/2009

\begin{abstract}
Resumo
Investidores têm buscado alternativas, tais como o arrendamento, o fomento, a venda de mudas, a difusão de tecnologia e suporte técnico, o que aumenta a área florestal e, consequentemente, a oferta de matéria-prima. No que se refere ao fomento, o termo é utilizado para caracterizar atividades centradas na promoção do desenvolvimento rural, tanto na área florestal como na agropecuária. A região estudada compreendeu a área de abrangência dos programas de parceria efetivados na região do Segundo Planalto Paranaense, através das modalidades "doação de mudas", "venda de mudas", "empreendimento", "pronaf" e "propflora". A tomada de dados se deu na forma de aplicação de questionários, com uma intensidade amostral de 249 entrevistados, distribuídos ao longo da área de estudo. Os parceiros das categorias "doação de mudas" e "pronaf" se caracterizam pelo uso dos recursos de produção voltado para a agricultura e pecuária de subsistência. As demais categorias, "venda de mudas", "empreendimento" e "propflora", utilizam seus fatores de produção em nível empresarial e com tecnologia mais intensiva. A quase totalidade das propriedades amostradas apresenta área destinada à Reserva Legal (RL) com valores acima daquele previsto por lei (20\%). Para a grande maioria dos parceiros amostrados, a parceria traz benefícios sociais (emprego), econômicos (renda) e ambientais (conservação da natureza).

Palavras-chave: Produção florestal; fomento florestal; expansão florestal.
\end{abstract}

\begin{abstract}
Models of forest expansion on second paranaense plateau: an analysis trough the social and economical profile of the landowners. Investors have searched alternatives to increase the forest raw material supply. Some alternatives are: lease, foment, selling of seedlings, forest technology diffusion and technical support. The studied region comprises the range area of the accomplished partnership programs in the region of "Paraná Second Plateau", containing the modalities: "donation of seedlings", "selling of seedlings", "enterprise", "PRONAF" and "PROPFLORA". The data were obtained through questionnaires, applied in a sampling intensity of 249 interviews. The categories "donation of seedlings" and "PRONAF" are characterized by productions related to agriculture and cattlerasing. The others categories, "selling of seedlings", "enterprise" and "PROPFLORA" use intensive technology and invest in bigger enterprises. Most of sampled properties have area destinated to Legal Reserve. Most of sampled partners bring social issues (job), economics issues (income) and environmental benefits (nature conservation).

Keywords: Forest production; forest promotion; forest expansion.
\end{abstract}

\section{INTRODUÇÃO}

Tendo em vista a estabilização e globalização da economia, empresas e profissionais do setor florestal estão revendo suas estratégias de expansão florestal, com o objetivo de aproveitar as oportunidades presentes e futuras no mercado de produtos florestais. Porém, a crescente demanda impulsionada pelo crescimento da indústria florestal tem tornado o acesso à terra mais difícil para 
investidores do setor, ocasionando relativa escassez de áreas para o cultivo de florestas. Nesse contexto, os investidores têm buscado alternativas, tais como o arrendamento, o fomento, a venda de mudas, a difusão de tecnologia e suporte técnico. Os resultados previstos são a minimização de aspectos sociais negativos, como o êxodo rural, e também a melhoria dos aspectos ambientais, através do aproveitamento racional dos recursos naturais disponíveis.

Para o setor privado, o fomento tem se mostrado como um mecanismo eficiente na ampliação da base florestal, visando o suprimento de matéria-prima para as indústrias do segmento madeireiro. $\mathrm{O}$ fomento florestal já integra as ações estratégicas das melhores empresas brasileiras (RUIZ, 2004).

Programas de fomento florestal em conjunto com os pequenos e médios proprietários de áreas rurais têm o objetivo de formar florestas em áreas ociosas e marginais das propriedades. Para Mendes (2005), o fomento é uma alternativa interessante para as pequenas propriedades, devendo a cultura florestal ser incentivada em áreas não-agricultáveis e como forma de poupança.

As áreas do fomento são incorporadas ao processo produtivo, com o objetivo de aumentar a base florestal da empresa, promovendo assim o desenvolvimento sustentável nas regiões e nos municípios (GONTIJO, 2004). Esses programas podem ser considerados como uma prática do desenvolvimento sustentável, garantindo uma futura poupança para os pequenos e médios proprietários, com o repasse para eles de reconhecidas práticas florestais da empresa (DIAS, 2004).

Segundo Delespinasse et al. (2006), os principais objetivos para a participação externa na produção de madeira das empresas são:

- maior integração da empresa com os pequenos e médios proprietários;

- fixação da mão-de-obra disponível na área rural;

- diminuição do investimento em terras através do desenvolvimento de fontes alternativas de suprimento de madeira;

- ampliação das alternativas de renda para os proprietários rurais na área de influência;

- diminuição dos custos de matéria-prima;

- ampliação das alternativas de produção de madeira para regular florestas próprias;

- diminuição da compra de madeira no mercado.

De acordo com Tomaselli; Siqueira (2006), o fator terra é de fundamental importância para o desenvolvimento do setor florestal, e é de pleno conhecimento da sociedade civil a existência de graves problemas no Brasil relacionados à gestão da política agrária, que vem afetando seriamente os mais diversos segmentos da economia nacional, com ênfase especial na indústria de base florestal, tanto a de florestas nativas como a de plantadas.

A função do Estado seria consolidar uma política florestal, com instrumentos legais, econômicos e administrativos para gerir a política agrária no Brasil. Uma dessas funções é promover o fomento florestal, ou seja, criar condições e/ou facilitar os meios para que a atividade florestal seja explorada, desde a formação de florestas homogêneas e a recuperação de áreas degradadas e matas ciliares, até o manejo de múltiplos produtos das florestas. Um dos programas desenvolvidos é o Programa Nacional de Fortalecimento da Agricultura Familiar (PRONAF), que tem como objetivo apoiar financeiramente as atividades agropecuárias e não-agropecuárias exploradas mediante emprego direto da força de trabalho do produtor rural e de sua família. Os beneficiários desse programa são produtores rurais, inclusive os remanescentes de quilombos e reservas indígenas, que se enquadram nos grupos especificados pelo programa, comprovados mediante "Declaração de Aptidão ao PRONAF - DAP" (MMA. 2006).

O financiamento rural do PRONAF tem impactos tanto sociais quanto econômicos, ao mesmo tempo em que dá condições para que os agricultores familiares ganhem em escala dentro da unidade de produção, além de manter as pessoas ocupadas, gerando empregos e possibilidades para que a família permaneça no meio rural. Além disso, diminui a tensão no campo e a pressão por emprego na cidade. Essas iniciativas contribuíram para que a participação da agricultura familiar no Produto Interno Bruto (PIB) nacional chegasse a 10,1\%, em 2003, segundo estudo realizado pela Fundação Instituto de Pesquisas Econômicas (FIPE), o que corresponde a um valor adicionado de $\mathrm{R}$ \$ 156,6 bilhões (MMA. 2006).

Outro programa do Governo Federal é o Programa de Plantio Comercial e Recuperação de Florestas (PROPFLORA), que tem como objetivos gerais e econômicos:

- implantação e manutenção de florestas destinadas ao uso industrial;

- recomposição e manutenção de áreas de preservação e reserva florestal legal; 
- implantação e manutenção de espécies florestais para produção de madeira destinada à queima no processo de secagem de produtos agrícolas;

- implantação de projetos silvipastoris (pecuária consorciada com floresta) e agroflorestais (agricultura consorciada com floresta);

- contribuir para a redução do déficit existente no plantio de árvores utilizadas como matérias-primas pelas indústrias;

- incrementar a diversificação das atividades produtivas no meio rural;

- gerar emprego e renda de forma descentralizada; e

- alavancar o desenvolvimento tecnológico e comercial do setor.

Do ponto de vista social e ambiental, esse programa visa fixar o homem no meio rural e reduzir a sua migração para as cidades, por meio da viabilização econômica de pequenas e médias propriedades, e contribuir para a preservação das florestas nativas e ecossistemas remanescentes. As operações são realizadas através de instituições financeiras credenciadas. Com o incentivo do PROPFLORA ao plantio de árvores exóticas de rápido crescimento, fornos para secagem de grãos, por exemplo, poderão ser abastecidos com espécies como o eucalipto, poupando as florestas nativas e reduzindo o desflorestamento (MMA, 2006).

Nesse contexto, o presente trabalho teve como objetivo analisar o perfil dos proprietários rurais do Segundo Planalto Paranaense que participam dos modelos de expansão florestal praticados pelas empresas da região em estudo, como subsídio para a elaboração de políticas sociais voltadas a melhorar a renda regional.

\section{MATERIAL E MÉTODOS}

A região estudada compreendeu os municípios de Tibagi, Ventania, Telêmaco Borba, Reserva, Ortigueira, Imbaú, São Jerônimo da Serra, Curiúva, Figueira e Sapopema, todos atendidos por programas de expansão florestal ofertados pela Klabin S.A., Unidade Paraná, empresa do segmento de papel e celulose.

As características das parcerias de expansão florestal praticadas são:

- "doação de mudas": nessa categoria, as empresas doam as mudas e o formicida. A EMATER (Empresa Paranaense de Assistência Técnica e Extensão Rural) seleciona os produtores, distribui as mudas e fornece a assistência técnica.

- "venda de mudas": nessa categoria, a empresa vende as mudas e o formicida, e o produtor paga em madeira na colheita.

- "empreendimento": nessa categoria, a empresa fornece insumos, operações e assistência técnica. O produtor faz o preparo do solo, a limpeza e o replantio. O pagamento é feito em madeira.

- "pronaf": nessa categoria, a empresa financia os pequenos agricultores através de recursos do ITAÚ BBA. A empresa paga o financiamento, no vencimento, e recebe em troca parte da madeira oriunda dos plantios. A EMATER fica responsável, conforme legislação, pela emissão da Declaração de Aptidão da propriedade.

- "propflora": nessa categoria, a empresa financia os agricultores através de recursos do ITAÚ BBA. A empresa paga o financiamento, no vencimento, e recebe em troca parte da madeira oriunda dos plantios. Os documentos requeridos junto aos produtores são a matrícula da propriedade e a negativa de dívida de tributos.

A tomada de dados se deu na forma de aplicação de questionários contendo questões abertas, semiabertas e fechadas, aplicados com uma intensidade amostral de 250 entrevistados, dentro de um universo de aproximadamente 3000 parceiros, distribuídos de forma relativamente homogênea ao longo da área de estudo. Os questionários foram aplicados junto ao produtor titular da parceria, ou, em casos específicos, junto ao membro da família que estivesse à frente das atividades desenvolvidas na propriedade. 
As variáveis do questionário abordaram temas relativos às condições sociais, econômicas e ambientais da família e da propriedade. O uso dos recursos de produção, as necessidades e anseios dos parceiros e a evolução de sua condição sócio-econômico-ambiental, também foram foco de análise.

\section{RESULTADOS E DISCUSSÃO}

\section{Categoria "doação de mudas"}

Os produtores que estabeleceram parcerias por "doação de mudas" estão, principalmente, em Imbaú: 32\%. Em segundo lugar vêm Figueira e Ortigueira, com 13\% cada. Reserva tem 10\%. Em São Jerônimo da Serra moram 8\% desses parceiros. Tibagi e Curiúva apresentam os mesmos índices, $7 \%$. Ventania aparece com $6 \%$ e Sapopema com 5\%. Na amostra em estudo, não há registro desse tipo de parceria em Telêmaco Borba.

A propriedade de quem faz parceria por “doação de mudas" tem área média de 22,60 ha, com máximo de 181 ha e mínimo de 2 ha. Os produtores têm, em média, 51 anos. O mais velho tem 78 anos; o mais jovem, 22 anos. A grande maioria das famílias mora na propriedade. Observou-se que, para o futuro desses filhos, a maioria dos casais deseja que estudem e morem na cidade (Figura 1).

Estudando a Região do Planalto Serrano Catarinense, Rochadelli et al. $(2008$, a) concluiu que a pequena propriedade tem como característica a utilização de programas de fomento para implantar seus maciços florestais. Segundo os autores, a escassez relativa de capital, a não especialização na produção florestal e a demanda por assistência técnica podem ser apontados como os principais fatores responsáveis para tal situação.

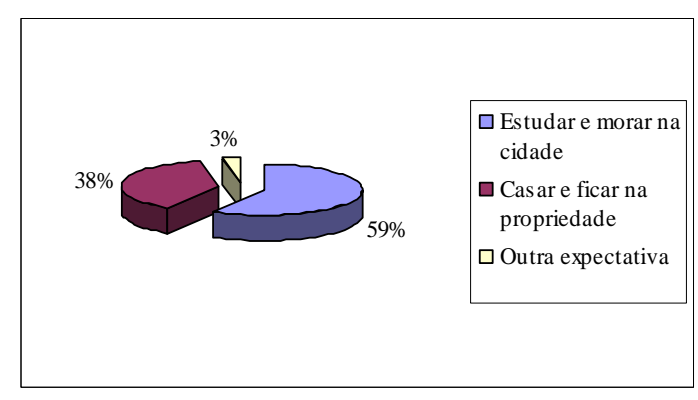

Figura 1. Expectativa familiar quanto ao destino da próxima geração.

Figure 1. Family expectation on the use of the next generation ("donation of seedlings").

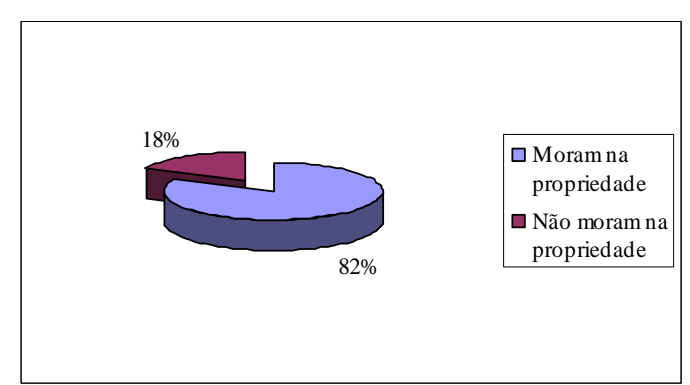

Figura 2. Local de instalação de moradia dos produtores rurais.

Figure 2. Site of the housing lodge of rural producers ("donation of seedlings").

As áreas em estudo ficam, em média, a $8 \mathrm{~km}$ da escola mais próxima. A propriedade mais distante está a $23 \mathrm{~km}$ desse serviço. Do atendimento público à saúde, os produtores estão, em média, a 8 km. Quem mora mais longe está a $32 \mathrm{~km}$. A sede do município está, em média, a $18 \mathrm{~km}$. Da rodovia, as fazendas ficam a, em média, $6 \mathrm{~km}$. A mais isolada está a $22 \mathrm{~km}$ do asfalto. De Telêmaco Borba, cidadepolo da região, as propriedades ficam, em média, a $37 \mathrm{~km}$.

Quanto ao uso da terra, a Reserva Legal ocupa, em média, 6 ha, ou $22 \%$ da área da propriedade. A maior mede 54 ha, ou $60 \%$ da fazenda; a menor, 0,4 ha, ou $8 \%$ da área. A lavoura permanente é cultivada, em média, em 3 ha. A lavoura temporária teve, na última safra, em média, 8 ha. A pastagem natural ocorre, em média, em 3 ha. A pastagem plantada aparece com 8 ha, em média. A área de ocorrência de floresta natural é de, em média, 6 ha. Os plantios florestais têm, em média 7 ha, ocupando $35 \%$ das propriedades. O maior tem 52 ha, ou 99\% da área; o menor, 0,25 ha, ou 0,71\%.

A produção florestal é entregue na propriedade por $83 \%$ dos entrevistados. $10 \%$ transportam as toras com veículos próprios e $7 \%$ terceirizam esse transporte.

Ao longo do ano, o emprego de mão de obra externa à propriedade se concentrou principalmente em novembro, com $61 \%$ das contratações. Outubro aparece em segundo lugar, com $11 \%$. Dezembro teve $7 \%$, agosto $4 \%$ e julho 3\%. Março e setembro tiveram 2\% cada. Maio e junho, 3\% cada. Janeiro e abril aparecem com $1 \%$ cada e em fevereiro não houve registros. 
Para $80 \%$ dos produtores, as informações que ajudam na tomada de decisões vêm da EMATER.

Perguntados sobre o que julgavam mais importante, se infraestrutura (estradas, luz e água), assistência técnica ou a formação profissional para os filhos, a grande maioria optou pela primeira opção (Figura 4).

Dentre os produtores que fizeram parcerias por "doação de mudas", $4 \%$ admitiram já ter pensado em abandonar as terras. Nesse caso, $60 \%$ venderiam a propriedade e $20 \%$ a arrendariam. Segundo Rochadelli et al. $(2008$, b), no Planalto Serrano Catarinense, o percentual de produtores que pensam em abandonar as terras é de $18 \%$. Segundo os autores, o principal motivo para tal é a idade avançada dos agricultores catarinenses, com a maioria apresentando idade superior a 60 anos. Quanto ao que fariam com a terra, $40 \%$ dos agricultores catarinenses venderiam e 50\% a arrendariam. A grande maioria dos proprietários tem título definitivo como documento das terras (Figura 3).

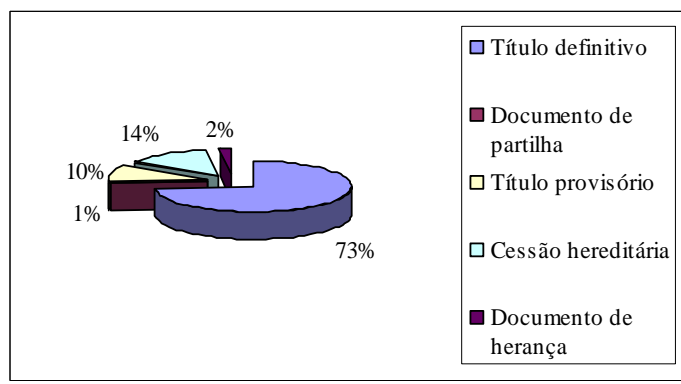

Figura 3. Documentação de posse da terra.

Figure 3. Documentation of land possession ("donation of seedlings")

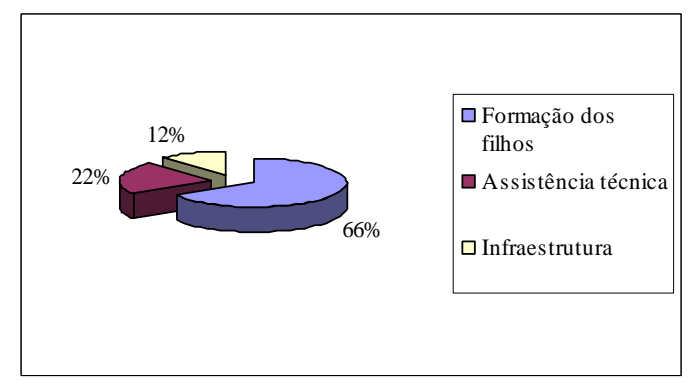

Figura 4. Grau de importância de benefícios.

Figure 4. Degree of importance of the benefits ("donation of seedlings").

Os plantios de eucalipto são cortados com 5 anos, em média. Os povoamentos de pinus são cortados com 20 anos. Para 13\% dos produtores, o corte fica a cargo da família. Para 2\%, essa tarefa é terceirizada. $85 \%$ preferem vender a madeira em pé. Para $98 \%$ dos agricultores, os plantios florestais representaram aumento na renda da família.

De forma sucinta, "doação de mudas" são os parceiros que:

- mais residem na propriedade (82\%);

- mais possuem Reserva Legal na propriedade (22\%);

- menos recebem assistência técnica florestal (52\%);

- mais preferem a venda dos produtos florestais na propriedade (83\%);

- menos recebem assistência técnica no manejo florestal (62\%).

\section{Categoria "venda de mudas"}

Os produtores que estabeleceram parcerias por "venda de mudas" têm suas propriedades sobretudo em Reserva, 43\%. Telêmaco Borba, São Jerônimo da Serra e Ortigueira têm todos o mesmo índice: 15\%. Sapopema e Imbaú aparecem com 7\% cada município. Nesta amostra, não há registro dessa categoria de parceria nos municípios de Tibagi, Curiúva, Figueira e Ventania.

As propriedades desta análise têm, em média, 109 ha. A idade média dos produtores é de 48 anos. Para o futuro desses jovens, a maioria dos pais espera que estudem e morem na cidade, ou então que casem e trabalhem na propriedade (Figura 5). A maioria das famílias mora na propriedade (Figura 6).

As fazendas desta amostra ficam, em média, a $6 \mathrm{~km}$ da escola. Do atendimento público à saúde, as propriedades estão, em média, a 7,06 km. Da sede do município, essas áreas ficam, em média, a $18 \mathrm{~km}$. Da rodovia, as fazendas distam, em média, $7 \mathrm{~km}$. De Telêmaco Borba, as propriedades estão, em média, a $62 \mathrm{~km}$.

A Reserva Legal ocupa, em média, 28 ha, o que corresponde a $21 \%$ da área da propriedade. A maior tem 145 ha, ou 55\% da área da fazenda. Não há registro, nesta amostra, da existência de lavouras permanentes. As lavouras temporárias foram cultivadas, na última safra, em média, em 8 ha. A pastagem natural aparece em apenas uma propriedade e tem 484 ha. A pastagem plantada tem, em média, 5,6 ha. A 
floresta natural ocorre, em média, em 16 ha. Os plantios florestais têm área média de 46 ha, o correspondente a $44 \%$ da fazenda. O maior tem 242 ha e ocupa a totalidade das terras dessa propriedade.

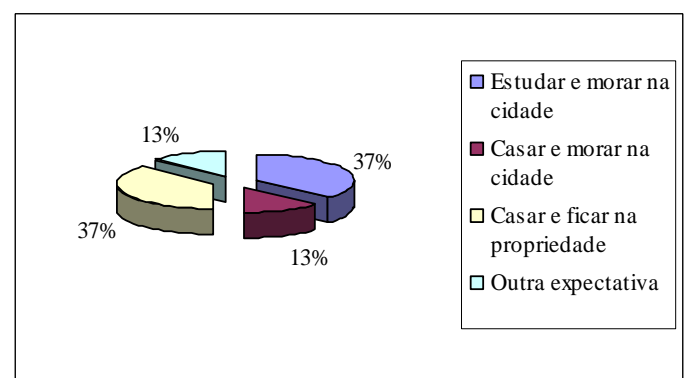

Figura 5. Expectativa familiar quanto ao destino da próxima geração.

Figure 5. Family expectation on the use of the next generation ("selling of seedlings").

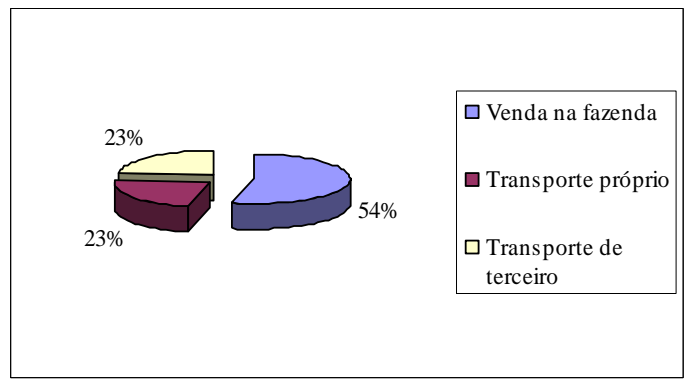

Figura 7. Forma de entrega do produto.

Figure 7. Form of delivery of the product ("selling of seedlings").

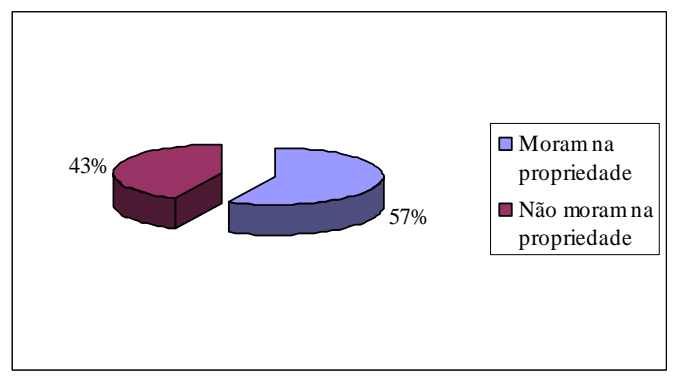

Figura 6. Local de instalação de moradia dos produtores rurais.

Figure 6. Site of the housing lodge of rural producers ("selling of seedlings").

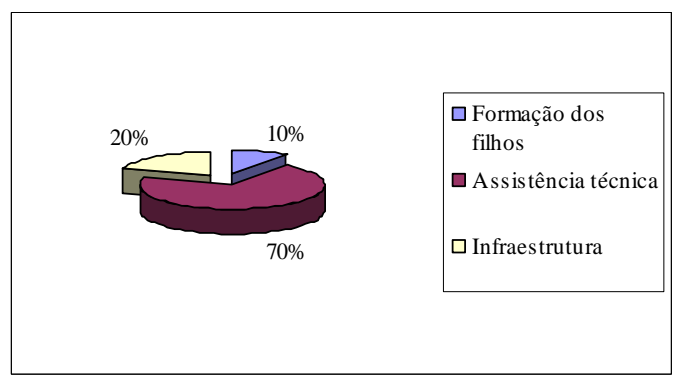

Figura 8. Grau de importância de benefícios.

Figure 8. Degree of importance of the benefits ("selling of seedlings").

Ao longo do ano, o emprego de mão de obra externa à propriedade foi maior em julho, com $18 \%$ das contratações. Setembro, dezembro e janeiro aparecem com $12 \%$ cada mês.

Para 36\% dos entrevistados, as informações que ajudam na tomada de decisões dentro da propriedade vêm da EMATER. Para 9\%, vêm de cooperativas.

Instados a responder o que julgavam mais importante, se infraestrutura (estradas, água e luz), assistência técnica ou a formação profissional dos filhos, a grande maioria dos entrevistados priorizou a assistência técnica (Figura 8). Essa posição diverge, de forma incisiva, daquela indicada pela categoria “doação de mudas". Isso se deve a questões de caráter social, tal qual o nível de renda disponível.

Nenhum dos produtores declarou já ter pensado em abandonar as terras. $64 \%$ dos proprietários têm título definitivo como documento das propriedades. $22 \%$ têm título provisório, $7 \%$ documento de compra e venda e $7 \%$ documento de herança.

Os plantios de eucalipto são cortados, em média, aos 6 anos. A idade mais frequente de corte é de 8 anos. Para $29 \%$ dos produtores, o corte é assunto de família. $14 \%$ terceirizam essa tarefa e $57 \%$ preferem entregar a madeira em pé. Para todos os entrevistados dessa amostra, os plantios florestais representaram aumento na renda da família.

De forma sucinta, "venda de mudas" são os parceiros que:

- mais possuem floresta plantada em \% (46\%);

- mais recebem assistência técnica florestal (92\%);

- menos preferem venda do produto florestal na propriedade (23\%);

- mais utilizam mão de obra familiar (3\%);

- menos pensam em abandonar a propriedade (0\%); 
- menos preferem pagamento em \% de madeira (24\%);

- mais preferem pagamento na entrega $(64 \%)$;

- menos pretendem reflorestar mais (64\%);

- mais conhecem técnicas de manejo (86\%).

\section{Categoria "empreendimento"}

A maior parte dos produtores que estabeleceram parcerias por "empreendimento" está dividida igualmente entre Reserva e Imbaú, com 23\% cada município. 13\% dos agricultores têm suas propriedades em Ventania. Em Tibagi e Telêmaco Borba, estão 11\% cada. 8\% estão em São Jerônimo da Serra. 6\%, em Ortigueira. O mesmo índice, 2\%, aparece em Curiúva e Figueira. Não há, nesta amostra, registro desse tipo de parceria em Sapopema.

As propriedades têm, em média, 220 ha. Os produtores têm 51 anos, em média. $51 \%$ das famílias moram na propriedade (Figura 10). $21 \%$ dos agricultores têm filhos menores de idade. Para o futuro desses jovens, a grande maioria dos casais espera que estudem e morem na cidade, ou então deseja outro tipo de futuro para os filhos, mas longe da propriedade (Figura 9). Os proprietários enquadrados nessa categoria tratam seu negócio como investimento e não demonstram dependência de mão de obra familiar, tanto para questões operacionais como gerenciais.

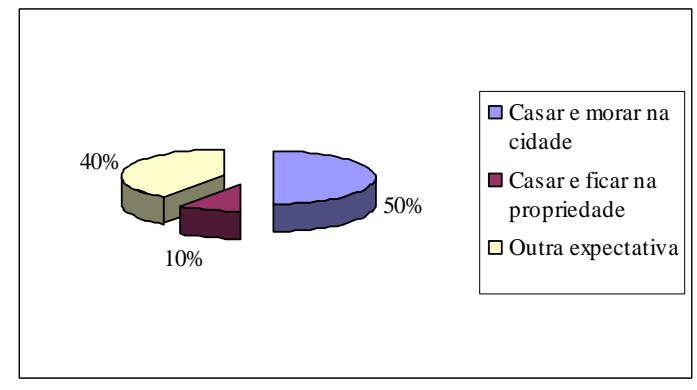

Figura 9. Expectativa familiar quanto ao destino da próxima geração.

Figure 9. Family expectation on the use of the next generation ("enterprise").

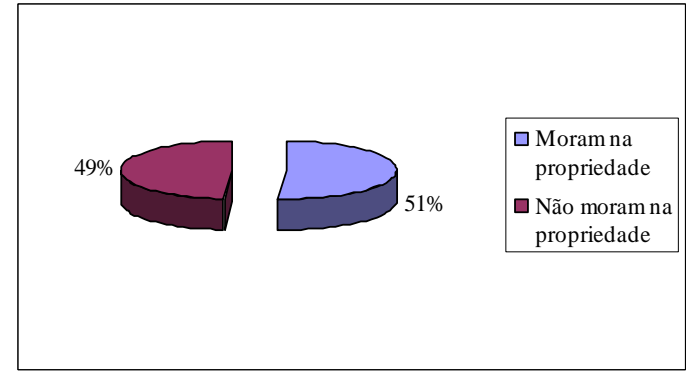

Figura 10. Local de instalação de moradia dos produtores rurais

Figure 10. Site of the housing lodge of rural producers ("enterprise").

Da escola mais próxima, as áreas em estudo ficam, em média, a $8 \mathrm{~km}$. O atendimento público de saúde está, em média, a $8 \mathrm{~km}$. A fazenda mais afastada fica a $24 \mathrm{~km}$. Da sede do município, as propriedades distam, em média, a $18 \mathrm{~km}$. Da rodovia, as propriedades estão a $9 \mathrm{~km}$, em média. De Telêmaco Borba, cidade-polo da região, as fazendas em análise ficam, em média, a $62 \mathrm{~km}$.

A Reserva Legal ocupa, em média, 22 ha, o que corresponde a $14 \%$ da propriedade. Entre as áreas em estudo, apenas uma apresenta lavoura permanente. A área desse cultivo é de 1300 ha. A lavoura temporária teve, na última safra, em média, 278 ha. A pastagem natural ocorre, em média, em 166 ha. A pastagem plantada aparece, em média, com 18 ha. A área média de ocorrência de floresta natural é de 117 ha. Os plantios florestais têm, em média, 43 ha, ou 36\% da área. O maior plantio tem 300 ha, ocupando toda a área útil da fazenda.

A produção florestal é entregue na propriedade por 34\% dos agricultores. 38\% transportam as toras com veículos próprios e $28 \%$ terceirizam o transporte da madeira (Figura 11). Todas as opções disponíveis no mercado são bem aproveitadas pelos produtores dessa categoria.

Ao longo do ano, o uso de mão de obra externa à propriedade se concentrou principalmente nos meses de setembro (17\%), outubro (17\%) e novembro (35\%). Em julho, foram $8 \%$. Os meses de janeiro, março, maio, junho e dezembro alcançaram o mesmo índice, $4 \%$. Em agosto e fevereiro não foram registradas contratações.

Para 56\% dos produtores, as informações que ajudam na tomada de decisões dentro da propriedade vêm da EMATER.

Perguntados sobre o que julgavam mais importante, se a infra-estrutura (estradas, luz e água), a assistência técnica ou a formação dos filhos, a maioria dos entrevistados priorizou formação profissional dos filhos e melhorias na infraestrutura; 17\%, pela assistência técnica (Figura 12). 


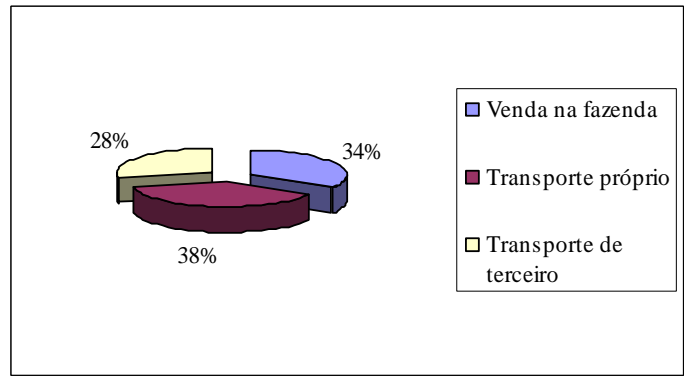

Figura 11. Forma de entrega do produto.

Figure 11. Form of delivery of the product ("enterprise").

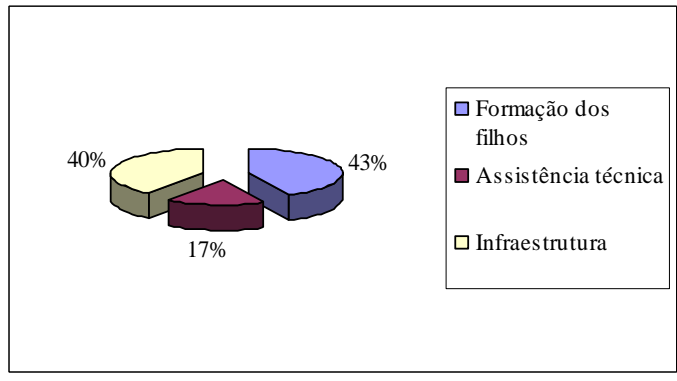

Figura 12. Grau de importância de benefícios.

Figure 12. Degree of importance of the benefits ("enterprise").

Nenhum dos proprietários declarou já ter pensado em abandonar as terras. $88 \%$ dos proprietários têm título definitivo da propriedade. $9 \%$ têm título provisório e $2 \%$ contrato de compra e venda. Os plantios de eucalipto são cortados, em média, aos 6 anos. Os povoamentos de pinus são cortados aos 15 anos. A idade mais frequente de corte é 6 anos.

Aproximadamente $76 \%$ dos produtores preferem vender a madeira em pé. Para $7 \%$, o corte das árvores é assunto de família. $17 \%$ preferem terceirizar essa tarefa. Para todos os entrevistados, os plantios florestais representaram aumento na renda da família.

De uma forma sucinta, "empreendimento" são os parceiros que:

- $\quad$ apresentam maior idade média (51 anos);

- menos têm filhos menores $(21 \%)$;

- menos possuem Reserva Legal (14\%);

- menos utilizam mão de obra familiar $(2 \%)$.

\section{Categoria "pronaf"}

Os produtores que estabeleceram parcerias através do "pronaf" têm suas propriedades principalmente em Reserva, 37\%; em Tibagi, 27\%. Em Curiúva, moram 17\% desses agricultores. Imbaú e Ortigueira apresentam o mesmo percentual, 7\%. Sapopema e Ventania também, 3\% cada município. Nesta amostra, não há registro desse tipo de parceria nos municípios de Telêmaco Borba, São Jerônimo da Serra e Figueira.

São, na maioria, propriedades de tamanho médio. A área é de 19 ha, em média. A quase totalidade dos produtores mora na propriedade (Figura 14), talvez não por opção, mas por necessidade. A terra é o único fator de produção que possuem. Para o futuro dos filhos, a maioria dos pais espera que casem e trabalhem na propriedade, ou então desejam outro tipo de futuro para os filhos (Figura 13). Observa-se que o pequeno produtor, mais dependente da mão de obra familiar, pretende manter os sucessores na propriedade.

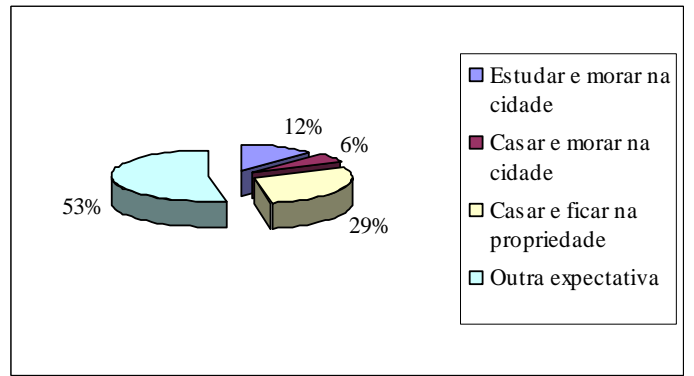

Figura 13. Expectativa familiar quanto ao destino da próxima geração.

Figure 13. Family expectation on the use of the next generation (“pronaf").

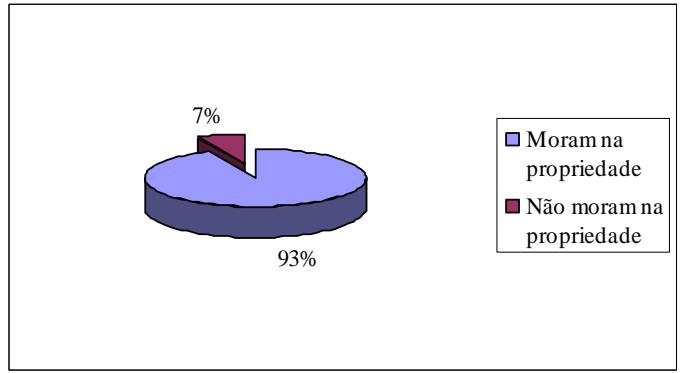

Figura 14. Local de instalação de moradia dos produtores rurais.

Figure 14. Site of the housing lodge of rural producers ("pronaf"). 
As propriedades ficam, em média, a $8 \mathrm{~km}$ da escola mais próxima. Do atendimento público de saúde, as propriedades estão, em média, a $9 \mathrm{~km}$. A sede do município fica, em média, a $20 \mathrm{~km}$ das áreas em análise. A mais próxima está a $1 \mathrm{~km}$. Da rodovia, as propriedades estão, em média, a $5 \mathrm{~km}$ de Telêmaco Borba, cidade-polo da região. Os produtores desse tipo de parceria estão, em média, a $64 \mathrm{~km}$.

Quanto ao uso da terra, essas propriedades têm, em média, 6 ha de Reserva Legal, o que corresponde a $17 \%$ da área da fazenda. Nesta amostra, não houve registro do cultivo de lavoura permanente. As lavouras temporárias ocuparam, em média, na última safra, 3 ha. A pastagem natural ocorre em apenas uma propriedade e tem 0,5 ha. A pastagem plantada apresenta área média de $5 \mathrm{ha}$. A área média de floresta natural é de 5 ha. Os plantios florestais têm, em média, 6 ha, o equivalente a $28 \%$ da propriedade.

A produção florestal é entregue na propriedade pela grande maioria dos agricultores (Figura 15). Poucos o fazem em veículos próprios. Uma pequena parcela terceiriza esse transporte. Observa-se que o pequeno produtor, com pouco recurso disponível, depende do mercado para entregar sua produção.

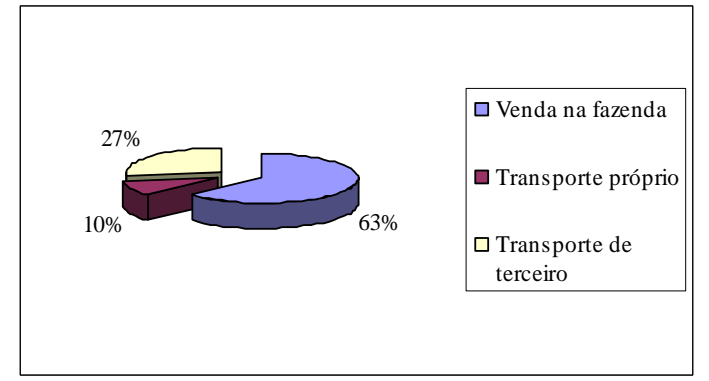

Figura 15. Forma de entrega do produto.

Figure 15. Form of delivery of the product ("pronaf").

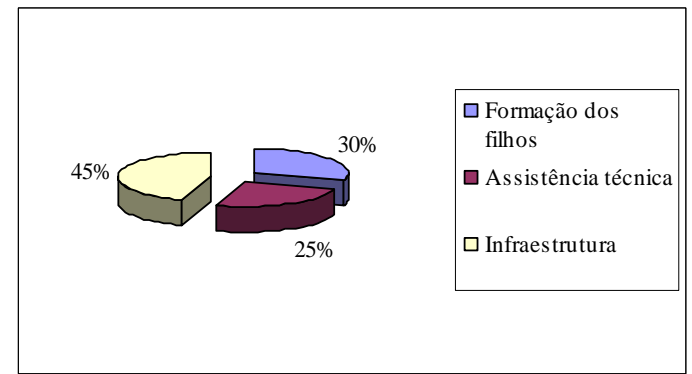

Figura 16. Grau de importância de benefícios.

Figure 16. Degree of importance of the benefits ("pronaf").

Ao longo do ano, o emprego de mão de obra externa à propriedade ficou concentrado quase que exclusivamente nos meses de setembro (12\%), outubro (21\%), novembro (17\%), dezembro (25\%) e janeiro (17\%). Em julho, aconteceram 8\% das contratações. Não houve registros nos outros meses.

Para 50\% dos produtores, as informações que ajudam na tomada de decisões dentro da propriedade vêm da EMATER.

Perguntados sobre o que julgavam mais importante, se infra-estrutura (estrada, luz e água), assistência técnica ou a formação profissional dos filhos, a maioria dos entrevistados priorizou a infraestrutura e a formação dos filhos (Figura 16). Mesmo não apresentando alta capacidade técnica, essa categoria não prioriza a necessidade de assistência técnica na atividade florestal.

Cerca de $15 \%$ dos produtores admitiram já ter pensado em abandonar as terras. Nesse caso, $25 \%$ as venderiam e $75 \%$ as arrendariam.

Os plantios de eucalipto são cortados, em média, com 7 anos. Os povoamentos de pinus são cortados aos 15 anos. Para 3\% dos produtores, o corte é um assunto de família. Um percentual igual, 3\%, terceiriza essa tarefa. $93 \%$ preferem vender a madeira em pé. Para todos os entrevistados desta amostra, os plantios florestais representaram aumento na renda da família.

De uma forma sucinta, "pronaf" são os parceiros que:

- possuem menor área média (19 ha);

- apresentam menor idade média (44 anos);

- mais moram na propriedade (93\%);

- mais possuem filhos menores $(63 \%)$;

- menos possuem floresta plantada \% (28\%);

- mais pensam em abandonar a propriedade (14\%);

- menos possuem título definitivo da terra (30\%);

- mais preferem pagamento em \% de madeira (72\%);

- menos preferem pagamento na entrega (28\%);

- mais pretendem reflorestar mais com fomento (85\%);

- menos conhecem técnicas de manejo florestal (52\%). 


\section{Categoria "propflora"}

O maior número de propriedades em que a parceria foi estabelecida pelo "propflora" está em Ortigueira, com $38 \%$. Reserva tem 23\%. Tibagi e Curiúva têm o mesmo índice, $15 \%$ cada município. $8 \%$ estão em Ventania. Nesta amostra, não foram registradas parcerias pelo "propflora" entre os produtores de Telêmaco Borba, Sapopema, São Jerônimo da Serra, Figueira e Imbaú.

São, principalmente, grandes propriedades. A área média é de 422 ha. Os produtores têm, em média, 48 anos. São poucas as famílias pertencentes a essa categoria que moram na propriedade (Figura 18). A maioria reside no meio urbano e tem a atividade florestal como opção de investimento. $54 \%$ dos casais têm filhos menores de idade. Para o futuro desses jovens, a grande maioria dos pais deseja que estudem e morem na cidade (Figura 17), denotando seu perfil empreendedor, que não depende de mão de obra familiar. Geralmente, esses proprietários possuem outras fontes de renda.

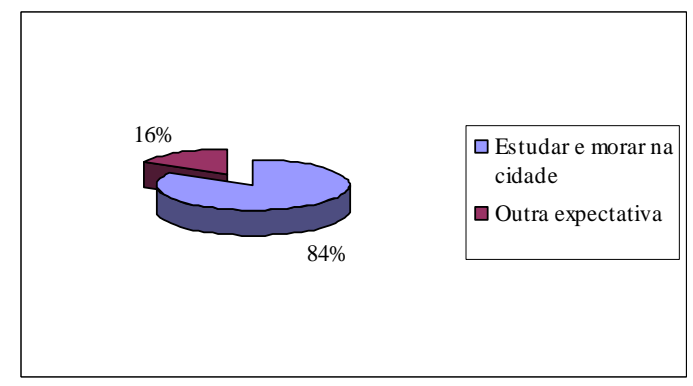

Figura 17. Expectativa familiar quanto ao destino da próxima geração.

Figure 17. Family expectation on the use of the next generation ("propflora").

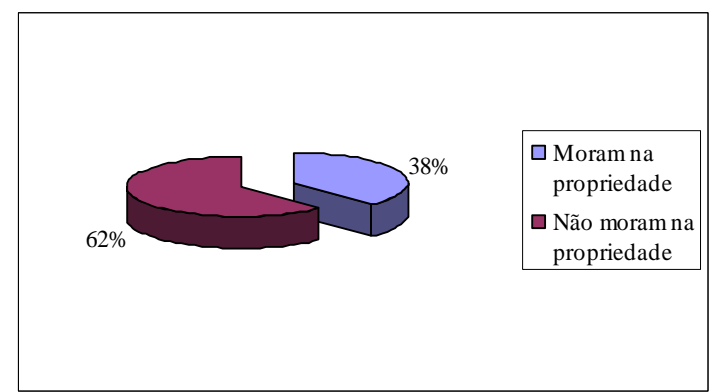

Figura 18. Local de instalação de moradia dos produtores rurais.

Figure 18. Site of the housing lodge of rural producers ("propflora").

As propriedades ficam, em média, a $11 \mathrm{~km}$ da escola mais próxima. Do atendimento público de saúde, as áreas em estudo estão, em média, a $11 \mathrm{~km}$. Da sede do município, as propriedades distam, em média, $19 \mathrm{~km}$. A mais próxima está a $4 \mathrm{~km}$. Da rodovia, as fazendas ficam, em média, a $11 \mathrm{~km}$. Telêmaco Borba, cidade-polo da região, está, em média, a $62 \mathrm{~km}$ dessas áreas.

A Reserva Legal ocupa, em média, 150 ha, o que corresponde a 18\% da área da propriedade. Nenhuma das propriedades em estudo desenvolve lavoura permanente. A lavoura temporária ocupou, na última safra, uma área média de 76 ha. As pastagens plantadas têm, em média, 68 ha. A floresta natural ocorre, em média, em 95 ha. Os plantios florestais têm 117 ha, em média, o equivalente a 28\% da propriedade.

A produção florestal é entregue na propriedade pela maioria dos produtores (Figura 19). Observa-se que essa categoria tem a atividade como opção de investimento, em que o produtor prefere entregar a madeira em pé e não se preocupar com a contratação de serviços de terceiros.

Ao longo do ano, a contratação de mão de obra externa à propriedade teve picos nos meses de outubro (14\%), novembro (18\%), dezembro (10\%) e março (10\%). Janeiro, fevereiro e setembro apresentaram $8 \%$ cada mês. Agosto e abril também registraram índices iguais entre si: $6 \%$. Maio, junho e julho repetem esse comportamento, $4 \%$ cada mês. De acordo com Rochadelli et al. (2008, c), a relação terra/trabalho é grande na região, visto que a grande maioria dos proprietários necessita do trabalho familiar em tempo integral. Em estudo no município de Viçosa, Minas Gerais, um trabalho de Fontes et al. (2003) revelou que a maioria dos produtores parceiros de programas de fomento florestal contratou mão de obra no período.

Para 69\% dos produtores, as informações que ajudam na tomada de decisões dentro da propriedade vêm da EMATER.

Instados a responder o que consideravam mais importante, se a infraestrutura (estradas, luz e água), a assistência técnica ou a formação profissional para os filhos, a maioria dos entrevistados priorizou a formação dos filhos (Figura 20), denotando a preocupação com o destino da próxima geração, perfil característico de grupos sociais mais desenvolvidos. 


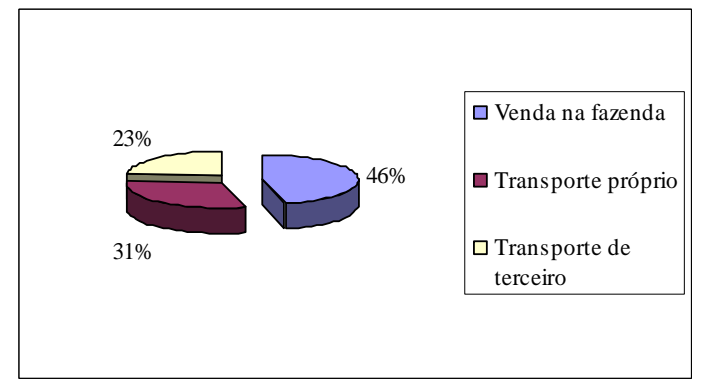

Figura 19. Forma de entrega do produto.

Figure 19. Form of delivery of the product ("propflora").

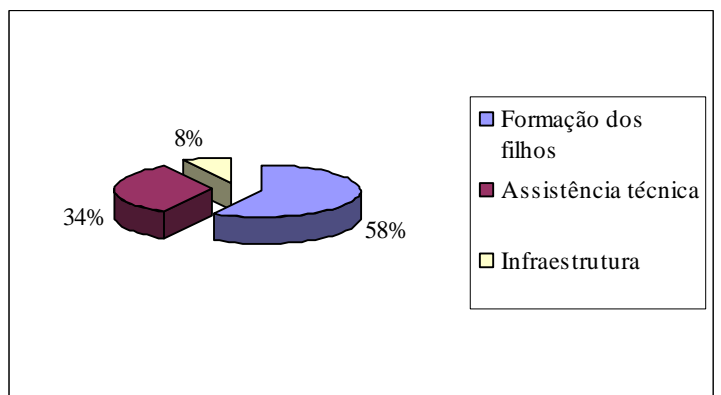

Figura 20. Grau de importância de benefícios.

Figure 20. Degree of importance of the benefits ("propflora").

Entre os produtores que fizeram parcerias pelo "propflora", 9\% admitiram já ter pensado em abandonar as terras. $92 \%$ dos proprietários têm título definitivo como documento da propriedade e $8 \%$ têm título provisório.

Os plantios de eucalipto são cortados, em média, com 7 anos. Os povoamentos de pinus são cortados com 21 anos. 92\% dos agricultores vendem a madeira em pé. 8\% terceirizam o corte. Para todos os amostrados desta categoria, o plantio florestal representou aumento na renda familiar.

De forma sucinta, "propflora" são os parceiros que:

- $\quad$ possuem maior área média (422 ha);

- menos moram na propriedade $(38 \%)$;

- mais possuem título definitivo da terra $(92 \%)$;

- mais pretendem reflorestar mais $(92 \%)$;

- menos pretendem reflorestar mais com fomento $(60 \%)$;

- mais recebem assistência técnica no manejo florestal (92\%).

\section{CONCLUSÕES}

- Os parceiros das categorias "doação de mudas" e "pronaf" se caracterizam pelo uso dos recursos de produção voltado para a agricultura e pecuária de subsistência. A atividade florestal entra no sistema de produção como um investimento de médio a longo prazo; uma poupança, capaz de capitalizar a propriedade quando de sua colheita. As demais categorias, "venda de mudas", "empreendimento" e "propflora", utilizam seus fatores de produção em nível empresarial e com tecnologia mais intensiva. Sua capacidade administrativa é maior e preferem fazer investimentos com recursos próprios.

- A quase totalidade das propriedades amostradas apresenta área destinada à Reserva Legal (RL) com valores acima do exigido (20\%), mostrando-se fiéis aos programas de expansão florestal.

- Para a quase totalidade dos parceiros amostrados, a parceria traz benefícios sociais (emprego), econômicos (renda) e ambientais (conservação da natureza). Entre as categorias analisadas, as que mais se beneficiam dos programas de expansão florestal são "doação de mudas" e "pronaf".

- Observou-se que há uma relação inversa entre o interesse em abandonar o meio rural e o tamanho das propriedades rurais. Os pequenos produtores são aqueles que mais pensam em abandonar o meio rural.

\section{AGRADECIMENTOS}

Klabin S.A., por permitir a publicação dos dados, resultado de pesquisa realizada em convênio com a Fundação de Pesquisas Florestais do Paraná (FUPEF) no ano de 2006.

\section{REFERÊNCIAS}

DELESPINASSE, B.; SIQUEIRA, J. D. P.; SARAIVA, G.; PITZAHN JUNIOR, E. Modelos de expansão da produção florestal e de desenvolvimento regional. Informativo STCP, Curitiba, n. 9. $2005 / 2006$ 
DIAS, G. L. S.; VIEIRA, C. A.; AMARAL, C. M. Comportamento do mercado de terras no Brasil. Disponível em: <(http://www.eclac.cl/publicaciones)>. Acesso em: 18/10/2004.

FONTES, A. A.; SILVA, M. L.; VALVERDE, S. R.; SOUZA, A. L. Análise da atividade florestal no Município de Viçosa-MG. Revista Árvore, Viçosa, MG, v. 27, n. 4, 2003.

GONTIJO, M. Mercado competitivo favorece fomento florestal. Disponível em: $<$ (http://www.miriangontijo.com.br) $>$. Acesso em: 20/11/2004.

MENDES, R. H. Caracterização do perfil dos proprietários rurais da região do planalto serrano catarinense. Dissertação (Mestrado em Economia e Política Florestal) - Setor de Ciências Agrárias, Universidade Federal do Paraná, Curitiba, 2005.

MMA - Ministério do Meio Ambiente: O plantio de florestas bate recorde em 2005. Disponível em http://www.mma.gov.br/index.php. Acesso em 2 ago. 2006.

ROCHADELLI, R.; MENDES, R. H.; SCHNEIDER, A. V.; MENON, C.; AUGUSTIN, C. R. Modelagem do perfil da gestão fundiária dos maciços florestais na Região do Planalto Serrano Catarinense. Revista Floresta, Viçosa, MG, v. 38, n. 1, jan.-mar. 2008 (a).

ROCHADELLI, R.; MENDES, R. H.; SCHNEIDER, A. V.; MENON, C.; AUGUSTIN, C. R. Expansão florestal na região do Planalto Serrano Catarinense: uma perspectiva a partir do perfil socioeconômico dos proprietários rurais. Revista Floresta, Viçosa, MG, v. 38, n. 3, jul.-set. 2008 (b).

ROCHADELLI, R.; SILVA, J. C. G. L.; RODRIGUES, F.; SCHNEIDER, A. V.; PETLA, D. Expansão florestal via fomento no Segundo Planalto Paranaense: uma abordagem a partir da estrutura fundiária das propriedades rurais da região. Revista Cerne, Lavras, v. 14, n. 2, abr.-jun. 2008 (c).

RUIZ, M. Fator de produção terra. Disponível em: <http://www.sociedadedigital.com.br >. Acesso em: $17 / 10 / 2004$.

TOMASELLI, I.; SIQUEIRA, J. D. P. Gestão fundiária inadequada: principal problema do setor florestal brasileiro. Informativo STCP, Curitiba, n. 9. 2005/2006. 